\title{
Elucidation of Acceleration Mechanisms by a Photosensitive Onium Salt for Nitroxide-Mediated Photocontrolled/Living Radical Polymerization
}

\author{
Eri Yoshida \\ Department of Environmental and Life Sciences, Toyohashi University of Technology, Toyohashi, Japan \\ Email: eyoshida@ens.tut.ac.jp
}

Received 5 June 2014; revised 1 July 2014; accepted 10 July 2014

Copyright (C) 2014 by author and Scientific Research Publishing Inc.

This work is licensed under the Creative Commons Attribution International License (CC BY).

http://creativecommons.org/licenses/by/4.0/

(c) (i) 0pen Access

\begin{abstract}
The acceleration mechanisms by a photosensitive onium salt for the nitroxide-mediated photocontrolled/living radical polymerization (photo-NMP) were determined. The photo-NMP of methyl methacrylate was performed by irradiation at room temperature using 4-methoxy-2,2,6,6-tetramethylpiperidine-1-oxyl (MTEMPO) as the mediator and (2RS, 2'RS)-azobis(4-methoxy-2,4-dimethylvaleronitrile) as the initiator. The polymerization was accelerated in the presence of (4-tertbutylphenyl)diphenylsulfonium triflate $\left({ }^{t} \mathrm{BuS}\right)$ to produce a polymer with a molecular weight distribution as narrow as the polymerization in its absence. $( \pm$ )-Camphor-10-sulfonic acid or 2-fluoro1-methylpyridinium $p$-toluenesulfonate had no effect on the polymerization speed, suggesting that ${ }^{t} \mathrm{BuS}$ did not serve as the photo-acid generator for the photo-NMP. It was found that the acceleration of the polymerization was based on the electron transfer from MTEMPO into ${ }^{t} \mathrm{BuS}$ in the excited state to temporarily generate a free radical propagating chain end and an oxoaminium salt (OAS), the one-electron oxidant of MTEMPO. This electron transfer mechanism was verified on the basis of the fact that the photo-NMP in the presence of ${ }^{\mathrm{B} u S}$ was still accelerated by triphenylamine, the electron transfer inhibitor, to partly produce a polymer with an uncontrolled molecular weight. The formation of an uncontrolled molecular weight polymer indicated the generation of a free radical propagating chain end due to the deactivation of the OAS by the triphenylamine. It was deduced that ${ }^{t} \mathrm{BuS}$ served as the electron acceptor from MTEMPO in the excited state to temporarily produce a free radical propagating chain end along with $\mathrm{OAS}$, resulting in the acceleration of the polymerization.
\end{abstract}

\section{Keywords}

Photocontrolled/Living Radical Polymerization, Acceleration Mechanisms, Electron Transfer, 
(4-tert-Butylphenyl)Diphenylsulfonium Triflate, 4-Methoxy-2,2,6,6-Tetramethylpiperidine-1-0xyl, Oxoaminium Salt

\section{Introduction}

The controlled/living radical polymerization (CLRP) has been an indispensable technique to design and create highly functional and efficient materials supporting today's cutting-edge technologies in many fields, such as drug and gene deliveries [1]-[4] and anti-bacterial treatment [5] in medical care, photolithography in electronics [6]-[8], water purification in environmental engineering [9], and surface modifications of wettability in the textile and vehicle industries [10]-[12]. The significance of the CLRP is the improvement of the functions by unifying the physical properties based on strict control of the molecular weight related to the structure of the polymers. Many CLRP systems have been established using various catalysts to provide well-controlled molecular weight polymers; e.g., the atom transfer radical polymerization (ATRP) [13] [14], reversible addition-fragmentation chain transfer (RAFT) [15], organoheteroatom-mediated polymerization [16], nitroxide-mediated polymerization (NMP) [17], iniferter polymerization [18], and iodide transfer polymerization [19] [20]. These thermal CLRPs produced a number of architectures with precisely controlled structures including supra molecules with high dimensional structures.

The photo-induced CLRP provides an environmental benefit, local application, and processing without thermal damage. The photo-CLRP to strictly control the molecular weights for various monomers was achieved by Yamago and coworkers using the organotellurium complex [21]. The photo-induced systems were also developed for the ATRP [22]-[24], RAFT [25], and iniferter polymerization [26] [27], although some of them still required heating to proceed [23] [24]. On the other hand, the photo-induced NMP to highly control a molecular weight have not been attained in spite of the fact that many efforts have been made using the mediators supported on the photosensitive groups [28]-[33]. In recent years, the photo-NMP using 4-methoxy-2,2,6,6-tetramethylpiperidine-1-oxyl (MTEMPO) has been reported to proceed at room temperature to produce polymers with a comparatively narrow molecular weight distribution $(\mathrm{Mw} / \mathrm{Mn} \approx 1.4)$ [34]-[47]. This photo-NMP was accelerated in the presence of an iron-arene complex [48] and photosensitive onium salts, such as the diarylidonium salts [34] [35] and triarylsulfonate salts [49] [50]. These onium salts served only as the accelerator for the polymerization and had no influence on the molecular weight control. However, the mechanisms of the acceleration by the onium salts were unclear, although possible mechanisms were proposed [51]-[53]. The present study determined that the acceleration by the onium salts for the photo-NMP was based on the electron transfer mechanism from MTEMPO to the onium salt in the excited state. This paper describes the acceleration mechanisms of the photo-NMP using a photosensitive triarylsulfonium salt.

\section{Experimental}

\subsection{Instrumentation}

The photopolymerization was carried out using an Ushio optical modulex BA-H502, an illuminator OPM2$502 \mathrm{H}$ with a high-illumination lens UI-OP2SL, and a $500 \mathrm{~W}$ super high-pressure UV lamp (USH-500SC2, Ushio Co. Ltd.). Gel permeation chromatography (GPC) was performed using a Tosoh GPC-8020 instrument equipped with a DP-8020 dual pump, a CO-8020 column oven, and a RI-8020 refractometer. Three polystyrene gel columns, Tosoh TSKGEL G2000H $\mathrm{HL}_{\mathrm{XL}}$, $\mathrm{G} 4000 \mathrm{H}_{\mathrm{XL}}$, and $\mathrm{G} 6000 \mathrm{H}_{\mathrm{XL}}$ were used with $N, N$-dimethylformamide as the eluent at $40^{\circ} \mathrm{C}$.

\subsection{Materials}

MTEMPO [54] and oxoaminium hexafluoroantimonate $\left(\mathrm{OASbF}_{6}\right)$ [55] were prepared as reported previously. (2RS, 2'RS)-Azobis(4-methoxy-2,4-dimethylvaleronitrile) ( $r$-AMDV) was obtained by separation from a mixture of the racemic and meso forms of 2,2'-azobis(4-methoxy-2,4-dimethylvaleronitrile) [56]. Methyl methacrylate (MMA) was washed with $5 \mathrm{wt} . \%$ sodium hydroxide solution and water, then distilled over calcium hydride. (4-tert-Butylphenyl)diphenylsulfonium triflate $\left({ }^{t} \mathrm{BuS}\right)$ was purchased from Sigma-Aldrich. ( \pm )-Camphor-10- 
sulfonic acid (CSA) was obtained from Wako Pure Chemical Industries. 2-Fluoro-1-methylpyridinium $p$ - toluenesulfonate (FPT) and triphenylamine were purchased from Tokyo Chemical Industry. These chemicals were used as received. Exrapure $\mathrm{N}_{2}$ gas with over 99.9995 vol\% was purchased from Taiyo Nippon Sanso Corporation.

\subsection{The Photo-NMP Using MTEMPO: General Procedure}

MMA (936.0 mg, $9.35 \mathrm{mmol}), r$-AMDV (14.0 mg, $0.0454 \mathrm{mmol})$, MTEMPO (9.0 mg, $0.0483 \mathrm{mmol})$, and ${ }^{t} \mathrm{BuS}$ (12.0 mg, $0.0256 \mathrm{mmol}$ ) were placed in an ampoule. The contents in the ampoule were degassed several times using a freeze-pump-thaw cycle and were charged with $\mathrm{N}_{2}$. The photopolymerization was carried out in the nitrogen atmosphere at room temperature for $5.5 \mathrm{~h}$ using a reflective light from a mirror in order to avoid any thermal polymerization caused by the direct irradiation. The product was dissolved in dichloromethane $(10 \mathrm{~mL})$. The solution was concentrated by an evaporator to remove the dichloromethane and unreacted monomer and was freeze-dried with benzene $(15 \mathrm{~mL})$ at $40^{\circ} \mathrm{C}$ to obtain the product as white powder $(657.1 \mathrm{mg})$. The monomer conversion was estimated gravimetrically. The product was dissolved in dichloromethane $(5 \mathrm{~mL})$ and poured into hexane $(500 \mathrm{~mL})$. The precipitate collected by filtration and dried in vacuo for several hours was subjected to GPC analysis.

\subsection{The Photo-NMP Using OAS: General Procedure}

MMA (936.0 mg, $9.35 \mathrm{mmol}$ ), $r$-AMDV (14.0 mg, $0.0454 \mathrm{mmol}$ ), and $\mathrm{OASbF}_{6}(20.4 \mathrm{mg}, 0.0483 \mathrm{mmol}$ ) were placed in an ampoule. The contents in the ampoule were degassed several times using a freeze-pump-thaw cycle and were charged with $\mathrm{N}_{2}$. The photopolymerization was carried out in the nitrogen atmosphere at room temperature for $5.5 \mathrm{~h}$ using a reflective light from a mirror. The product was dissolved in dichloromethane $(10 \mathrm{~mL})$. The solution was concentrated by an evaporator to remove the dichloromethane and unreacted monomer and was freeze-dried with benzene $(10 \mathrm{~mL})$ at $40^{\circ} \mathrm{C}$ to obtain the product as white powder $(299.0 \mathrm{mg})$. The monomer conversion was estimated gravimetrically. The product was dissolved in dichloromethane $(1.5 \mathrm{~mL})$ and poured into hexane $(200 \mathrm{~mL})$. The precipitate collected by filtration and dried in vacuo for several hours was subjected to GPC analysis.

\section{Results and Discussion}

The photo-NMP of MMA was performed at room temperature for $5.5 \mathrm{~h}$ using MTEMPO as the mediator and $r$-AMDV as the initiator in the presence of ${ }^{t} \mathrm{BuS}$. The polymerization was accelerated by ${ }^{t} \mathrm{BuS}$ at a 0.53 molar ratio to MTEMPO to produce poly(MMA) at a $68 \%$ MMA conversion $(\mathrm{Mn}=13,600$, $\mathrm{Mw} / \mathrm{Mn}=1.43)$, whereas the polymerization in the absence of ${ }^{t} \mathrm{BuS}$ yielded a polymer at a $35 \%$ conversion $(\mathrm{Mn}=8490, \mathrm{Mw} / \mathrm{Mn}=1.40)$. It was confirmed that ${ }^{t} \mathrm{BuS}$ played a role only as the accelerator because the polymerization provided a molecular weight distribution as narrow as that by the polymerization in its absence. The photosensitive onium salts are often used as a proton source in many photoreactions by eliminating a proton from the solvent or monomer in the excited state [57]. While the photosensitive onium salts serve as a photo-acid generator, the salts also act as an electron acceptor in the presence of an electron donor in the excited state [58] [59]. Hence, two mechanisms are considered for the cause of the acceleration by ${ }^{t} \mathrm{BuS}$ for the MTEMPO-mediated photopolymerization as shown in Scheme 1. The polymerization should be accelerated by the protonation to MTEMPO when ${ }^{t} \mathrm{BuS}$ serves as the photo-acid generator, whereas the acceleration is caused by the temporary generation of a free radical propagating chain end along with the formation of an oxoaminium salt (OAS), the one-electron oxidant of MTEMPO, when ${ }^{t} \mathrm{BuS}$ acts as the electron acceptor.

In order to clarify the mechanisms of the acceleration by ${ }^{t} \mathrm{BuS}$, the possible mechanism of ${ }^{t} \mathrm{BuS}$ as the photoacid generator was first explored. For the thermal nitroxide-mediated controlled/living radical polymerization, CSA and FPT accelerated the polymerization by serving as a proton donor or a Lewis acid [60]. These acids were adopted as the accelerator instead of ${ }^{t} \mathrm{BuS}$ for the MTEMPO-mediated photopolymerization (Table 1). Neither CSA nor FPT produced a significant difference in the MMA conversion and molecular weight distribution of the resulting polymers, indicating that the polymerization was not accelerated in the presence of the acid. Consequently, the role of ${ }^{t} \mathrm{BuS}$ as the photo-acid generator is negated for the acceleration of the polymerization.

When ${ }^{t} \mathrm{BuS}$ acts as the electron acceptor from MTEMPO, the OAS is temporarily generated in the excited state. In order to verify this electron transfer mechanism for the acceleration, the polymerization using $\mathrm{OASbF}_{6}$ 


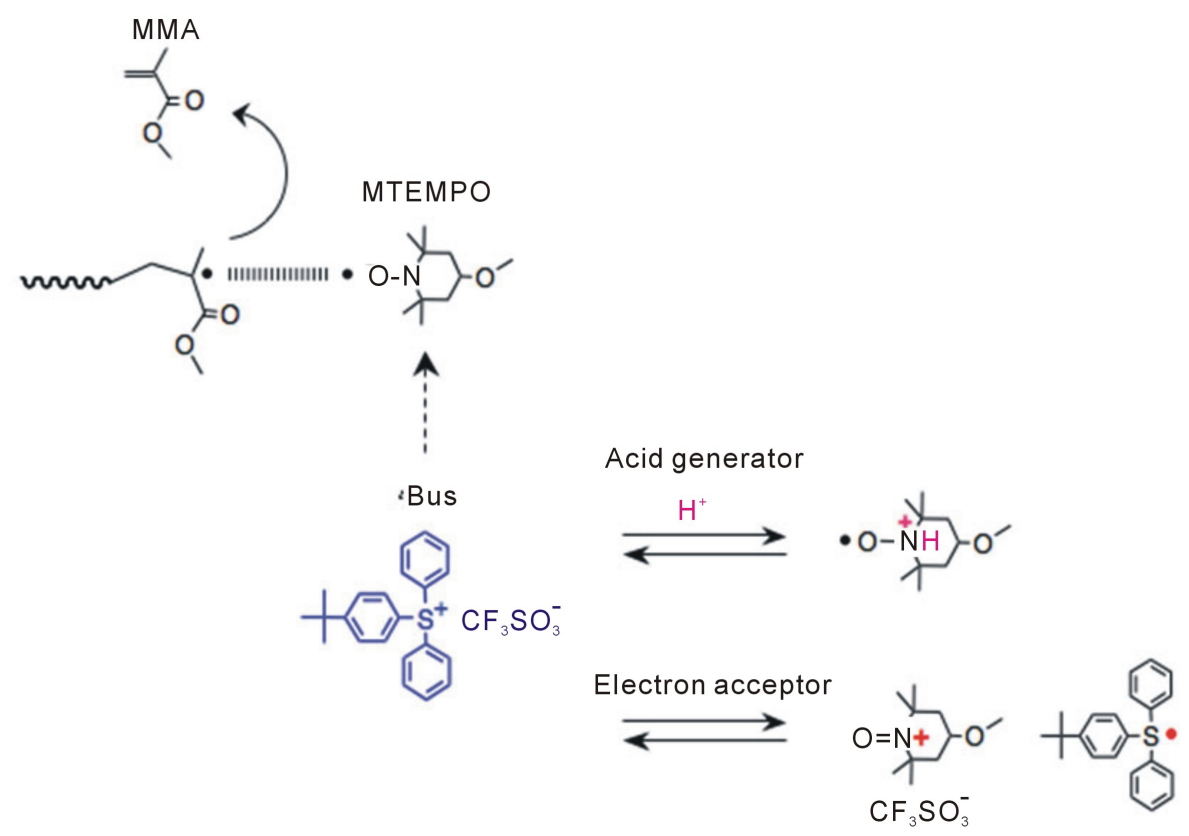

Scheme 1. The acceleration mechanisms of the photo-NMP by ${ }^{t} \mathrm{BuS}$.

Table 1. The photo-NMP using MTEMPO in the presence of acid ${ }^{\mathrm{a}}$.

\begin{tabular}{cccc}
\hline Acid & Conversion (\%) & $\mathrm{Mn}^{\mathrm{b}}$ & $\mathrm{Mw}^{\mathrm{C}} \mathrm{Mn}^{\mathrm{b}}$ \\
CSA & 30 & 7990 & 1.36 \\
FPT & 42 & 9250 & 1.40 \\
& 35 & 8490 & 1.40 \\
\hline
\end{tabular}

a. Acid/MTEMPO $=0.53$, MTEMPO $/ r$-AMVD $=1.06$. Polymerization time $=5.5$ h. b. Estimated by GPC based on PMMA standards.

instead of MTEMPO was investigated. The polymerization using $\mathrm{OASbF}_{6}$ in the absence of ${ }^{t} \mathrm{BuS}$ produced a polymer at a $31 \%$ conversion $(\mathrm{Mn}=9670, \mathrm{Mw} / \mathrm{Mn}=1.35)$ at a 1.06 molar ratio of $\mathrm{OASbF}_{6} / r-\mathrm{AMDV}$, while the MTEMPO-mediated polymerization yielded a polymer at a $35 \%$ conversion $(\mathrm{Mn}=8490, \mathrm{Mw} / \mathrm{Mn}=1.40)$ at the identical molar ratio of MTEMPO/r-AMDV. The polymerization by $\mathrm{OASbF}_{6}$ produced a polymer with a comparatively narrow molecular weight distribution at a conversion similar to that for the polymerization by MTEMPO, implying that $\mathrm{OASbF}_{6}$ served as the mediator to control the molecular weight as did MTEMPO. It is expected that the oxoaminium cation eliminated an electron from the counter anion to convert into MTEMPO in the excited state because it is difficult to eliminate an electron from the propagating radical chain end attached to the electron-withdrawing group. The conversion of the oxoaminium cation to MTEMPO by the electron elimination from the counter anion is supported by previous reports that the OAS eliminated an electron from electron donors to provide their radical cations, and converting into MTEMPO [61]-[65]. Accordingly, the polymerization was examined in the presence of the electron transfer inhibitor, triphenylamine. These results are summarized in Table 2. The MTEMPO-mediated polymerization was retarded by triphenylamine. This retardation was caused by preventing the bond cleavage between the propagating radical and MTEMPO due to more electron-donating triphenylamine, resulting in no influence on the molecular weight distribution. On the other hand, the $\mathrm{OASbF}_{6}$-mediated polymerization was accelerated by the triphenylamine, accompanied by the formation of a polymer with an uncontrolled molecular weight over 1,000,000. The ratio of the polymer with the uncontrolled molecular weight to that with the controlled molecular weight was estimated to be $0.454 / 0.546$ for $\mathrm{Mn}=$ $1,630,000 / 10,300$ based on the area percent by the GPC analysis. The formation of the polymer with the uncontrolled molecular weight implies the generation of a free radical propagating chain end without the counter radical of the mediator, indicating the deactivation of $\mathrm{OASbF}_{6}$. This deactivation is considered to occur by the $\beta$ elimination of $\mathrm{OASbF}_{6}$ by the triphenylamine (Scheme 2). The triphenylamine has the potential to act as the 
Table 2. The photo-NMP in the presence of triphenylamine ${ }^{\text {a }}$.

\begin{tabular}{cccccc}
\hline Mediator & $\mathrm{Ph}_{3} \mathrm{~N} /$ Mediator & Time $(\mathrm{h})$ & Conversion $(\%)$ & $\mathrm{Mn}^{\mathrm{b}}$ & $\mathrm{Mw} / \mathrm{Mn}^{\mathrm{b}}$ \\
\hline MTEMPO & 1.0 & 7.0 & 22 & 5200 & 1.35 \\
MTEMPO & 0 & 5.5 & 35 & 8490 & 1.40 \\
& & 5.5 & 49 & $1,630,000^{\mathrm{c}}$ & 2.88 \\
OASbF6 & 1.0 & & & 10,300 & 1.47 \\
OASbF6 & 0 & 5.5 & 31 & 9670 & 1.35 \\
\hline
\end{tabular}

a. Mediator $/ r$-AMVD $=1.06$. b. Estimated by GPC based on PMMA standards. c. The ratio of the area $\%$ for Mn $=1,630,000 / 10,300$ was $0.454 / 0.546$.

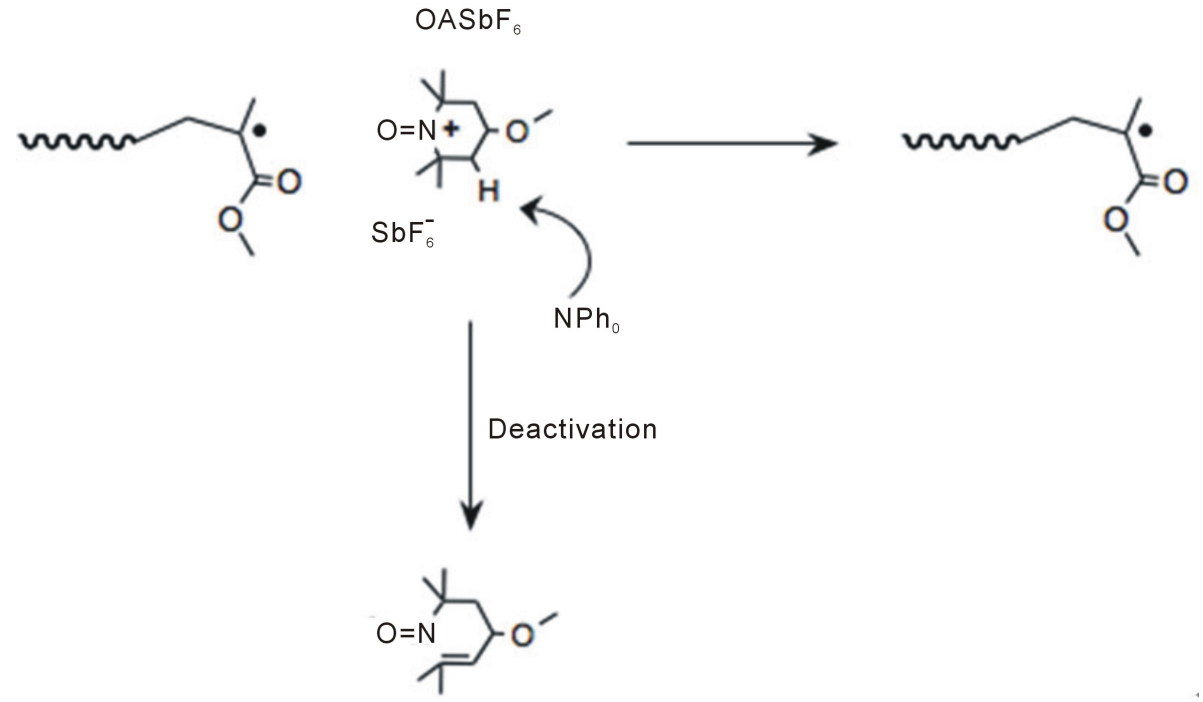

Scheme 2. The generation of a free radical propagating chain end based on the deactivation of $\mathrm{OASbF}_{6}$ by the triphenylamine.

electron donor to $\mathrm{OASbF}_{6}$, however this possibility is negated because $\mathrm{OASbF}_{6}$ should be converted into MTEMPO to control the molecular weight if the electron transfer occurs from the triphenylamine to $\mathrm{OASbF}_{6}$.

In order to verify the formation of the OAS in the excited state by the electron transfer from MTEMPO to ${ }^{t} \mathrm{BuS}$, the acceleration by ${ }^{t} \mathrm{BuS}$ for the MTEMPO-mediated photopolymerization was explored in the presence of the triphenylamine. The results are shown in Table 3. The triphenylamine significantly increased the polymerization rate, accompanied by broadening of the molecular weight distribution, indicating the formation of a polymer with an uncontrolled molecular weight. This uncontrolled molecular weight along with the rapid polymerization is caused by the generation of a free radical propagating chain end losing the mediator radical based on the deactivation of the OAS by the triphenylamine. It was confirmed that the OAS was formed in the excited state by the electron transfer from MTEMPO to ${ }^{t} \mathrm{BuS}$ (Scheme 3). ${ }^{t} \mathrm{BuS}$ served as the electron acceptor to temporarily produce the OAS along with a free radical propagating end. The electron transfer from MTEMPO in the excited state lengthens the time for which the propagating radical is in the free state, causing an increase in the number of monomers inserted between the propagating radical and MTEMPO. Hence, this longer free state time of the propagating radical resulted in the acceleration of the polymerization. The propagating radical is coupled again with MTEMPO formed by the reverse electron transfer from the ${ }^{t} \mathrm{BuS}$ radical to the OAS. This reverse electron transfer maintains the molecular weight control of the polymerization against the acceleration by ${ }^{t} \mathrm{BuS}$.

The electron transfer mechanism for the acceleration by ${ }^{t} \mathrm{BuS}$ is supported by the photo-NMP of glycidyl methacrylate (GMA) [66]. The uncontrolled photopolymerization initiated by $r$-AMDV in the presence of ${ }^{t} \mathrm{BuS}$ provided a gel product due to the simultaneous progress of the free radical polymerization of the vinyl groups by $r$ AMDV and the cationic ring-opening polymerization of the epoxy group by ${ }^{t} \mathrm{BuS}$ serving as the photo-acid generator [60]. On the other hand, the photo-NMP using MTEMPO in the presence of ${ }^{t}$ BuS produced a poly(GMA) obtained only by the vinyl group polymerizing and retained the epoxy groups in the structure, supporting the fact 
Table 3. The acceleration by triphenylamine for the photo-NMP in the presence of ${ }^{t} \mathrm{BuS}^{\mathrm{a}}$.

\begin{tabular}{ccccc}
\hline $\mathrm{Ph}_{3} \mathrm{~N} / \mathrm{B}$ BS & Time (h) & Conversion (\%) & $\mathrm{Mn}^{\mathrm{b}}$ & $\mathrm{Mw} / \mathrm{Mn}^{\mathrm{b}}$ \\
\hline 1.0 & 2.5 & 88 & 18,600 & 2.32 \\
0 & 5.5 & 68 & 13,600 & 1.43 \\
\hline
\end{tabular}

a. $\mathrm{MTEMPO} / \mathrm{r}-\mathrm{AMVD}=1.06,{ }^{\mathrm{t}} \mathrm{BuS} / \mathrm{MTEMPO}=0.53$. b. Estimated by GPC based on PMMA standards.

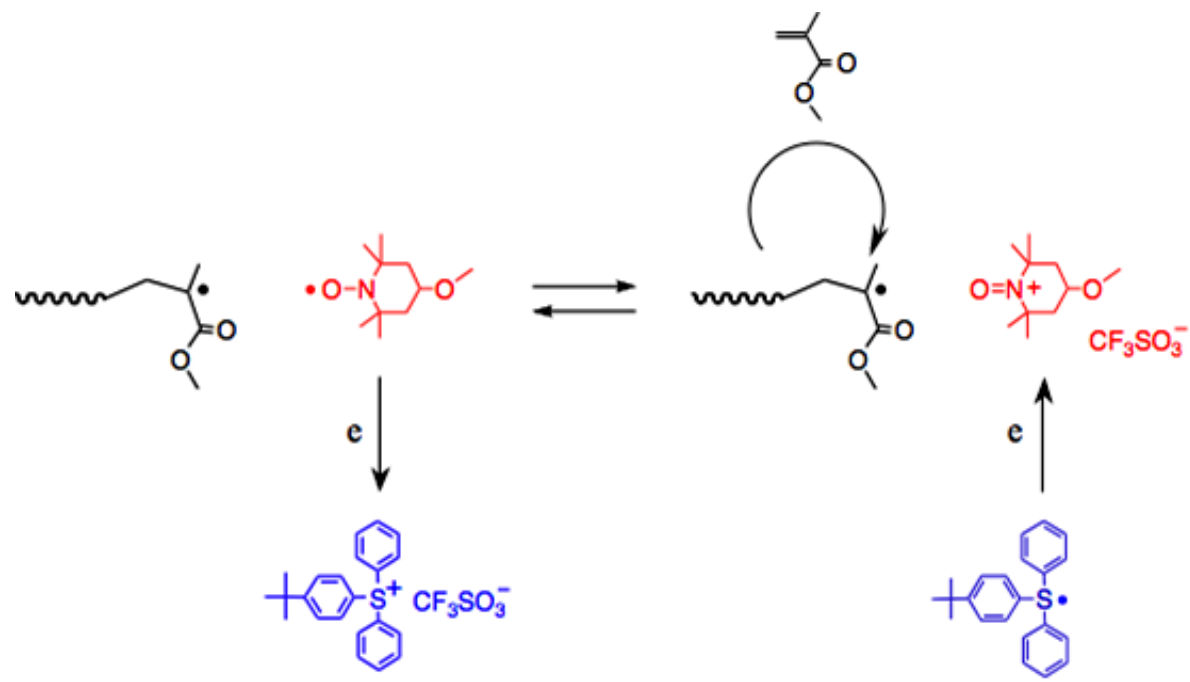

Scheme 3. The electron transfer mechanism for the acceleration of the photo-NMP by ${ }^{t} \mathrm{BuS}$.

that ${ }^{t} \mathrm{BuS}$ served as the electron acceptor from MTEMPO during the photo-NMP.

\section{Conclusion}

The acceleration mechanisms by the photosensitive onium salts for the photo-NMP were determined. The onium salts did not serve as the photo-acid generator, but as the electron acceptor from MTEMPO to temporarily produce the OAS along with a free radical propagating end in the excited state. The formation of the OAS by the electron transfer was confirmed by obtaining a polymer with an uncontrolled molecular weight by the polymerization in the presence of the electron transfer inhibitor. The conversion from MTEMPO into the OAS in the excited state lengthened the time for which the propagating radical was in the free state, resulting in the acceleration of the polymerization. MTEMPO that was reproduced by the reverse electron transfer from the onium radical to the OAS controlled the molecular weight.

\section{Acknowledgements}

The author is thankful for a JSPS Grant-in-Aid for Scientific Research (Grant Number 25390003).

\section{References}

[1] Liu, Y., Klep, V. and Luzinov, I. (2006) To Patterned Binary Polymer Brushes via Capillary Force Lithography and Surface-Initiated Polymerization. Journal of American Chemical Society, 128, 8106-8107. http://dx.doi.org/10.1021/ja061646f

[2] Zhou, F., Zheng, Z., Yu, B., Liu, W. and Huck, W.T.S. (2006) Multicomponent Polymer Brushes. Journal of American Chemical Society, 128, 16253-16258. http://dx.doi.org/10.1021/ja0654377

[3] Scales, C.W., Huang, F., Li, N., Vasilieva, Y.A., Ray, J., Convertine, A.J. and McCormick, C.L. (2006) Corona-Stabilized Interpolyelectrolyte Complexes of SiRNA with Nonimmunogenic, Hydrophilic/Cationic Block Copolymers Prepared by Aqueous RAFT Polymerization. Macromolecules, 39, 6871-6881. http://dx.doi.org/10.1021/ma061453c

[4] Giacomelli, C., Schmidt, V. and Borsali, R. (2007) Nanocontainers Formed by Self-Assembly of Poly(Ethylene Oxide)b-Poly(Glycerol Monomethacrylate)_Drug Conjugates. Macromolecules, 40, 2148-2157. 
http://dx.doi.org/10.1021/ma062562u

[5] Ting, S.R.S., Min, E., Escalé, P., Save, M., Billon, L. and Stenzel, M.H. (2009) Lectin Recognizable Biomaterials Synthesized via Nitroxide-Mediated Polymerization of a Methacryloyl Galactose Monomer. Macromolecules, 42, 9422-9434. http://dx.doi.org/10.1021/ma9019015

[6] Zhang, F., Shi, Z.L., Chua, P.H., Kang, E.T. and Neoh, K.G. (2007) Functionalization of Titanium Surfaces via Controlled Living Radical Polymerization: From Antibacterial Surface to Surface for Osteoblast Adhesion. Industrial and Engineering Chemistry Research, 46, 9077-9086. http://dx.doi.org/10.1021/ie070795j

[7] Werne, T.A., Germack, D.S., Hagberg, E.C., Sheares, V.V., Hawker, C.J. and Carter, K.R. (2003) A Versatile Method for Tuning the Chemistry and Size of Nanoscopic Features by Living Free Radical Polymerization. Journal of American Chemical Society, 125, 3831-3838. http://dx.doi.org/10.1021/ja028866n

[8] Teare, D.O.H., Schofield, W.C.E., Garrod, R.P. and Badyal, J.P.S. (2005) Rapid Polymer Brush Growth by TEMPOMediated Controlled Free-Radical Polymerization from Swollen Plasma Deposited Poly(maleic anhydride) Initiator Surfaces. Langmuir, 21, 10818-10824. http://dx.doi.org/10.1021/la051566+

[9] Saleh, N., Phenrat, T., Sirk, K., Dufour, B., Ok, J., Sarbu, T., Matyjaszewski, K., Tilton, R.D. and Lowry, G.V. (2005) Adsorbed Triblock Copolymers Deliver Reactive Iron Nanoparticles to the Oil/Water Interface. Nano Letters, 5, 24892494. http://dx.doi.org/10.1021/nl0518268

[10] Pyun, J. and Matyjaszewski, K. (2001) Synthesis of Nanocomposite Organic/Inorganic Hybrid Materials Using Controlled/“Living” Radical Polymerization. Chemistry of Materials, 13, 3436-3448. http://dx.doi.org/10.1021/cm011065j

[11] Andruzzi, L., Hexemer, A., Li, X., Ober, C.K., Kramer, E.J., Galli, G., Chiellini, E. and Fischer, D.A. (2004) Control of Surface Properties Using Fluorinated Polymer Brushes Produced by Surface-Initiated Controlled Radical Polymerization. Langmuir, 24, 10498-10506. http://dx.doi.org/10.1021/la049264f

[12] Idota, N., Nagase, K., Tanaka, K., Okano, T. and Annaka, M. (2010) Stereoregulation of Thermoresponsive Polymer Brushes by Surface-Initiated Living Radical Polymerization and the Effect of Tacticity on Surface Wettability. Langmuir, 26, 17781-17784. http://dx.doi.org/10.1021/la1024229

[13] Matyjaszewski, K. and Xia, J. (2001) Atom Transfer Radical Polymerization. Chemical Reviews, 101, 2921-2990. http://dx.doi.org/10.1021/cr940534g

[14] Kamigaito, M., Ando, T. and Sawamoto, M. (2001) Metal-Catalyzed Living Radical Polymerization. Chemical Reviews, 101, 3689-3746. http://dx.doi.org/10.1021/cr9901182

[15] Moad, G., Rizzardo, E. and Thang, S.H. (2008) Toward Living Radical Polymerization. Accounts of Chemical Research, 41, 1133-1142. http://dx.doi.org/10.1021/ar800075n

[16] Yamago, S. (2009) Precision Polymer Synthesis by Degenerative Transfer Controlled/Living Radical Polymerization Using Organotellurium, Organostibine, and Organobismuthine Chain-Transfer Agents. Chemical Reviews, 109, 50515068. http://dx.doi.org/10.1021/cr9001269

[17] Hawker, C.J., Bosman, A.W. and Harth, E. (2001) New Polymer Synthesis by Nitroxide Mediated Living Radical Polymerizations. Chemical Reviews, 101, 3661-3688. http://dx.doi.org/10.1021/cr990119u

[18] Otsu, T. (2000) Iniferter Concept and Living Radical Polymerization. Journal Polymer Science, Part A, Polymer Chemistry, 38, 2121-2136. http://dx.doi.org/10.1002/(SICI)1099-0518(20000615)38:12<2121::AID-POLA10>3.0.CO;2-X

[19] Tatemoto, M., Yutani, Y. and Fujiwara, K. (1988) Novel Iodine-Containing Compound, Preparation Thereof and Block Copolymer Comprising the Same. European Patent 272698 A2.

[20] David, G., Boyer, C., Tonnar, J., Ameduri, B., Lacroix-Desmazes, P. and Boutevin, B. (2006) Use of Iodocompounds in Radical Polymerization. Chemical Reviews, 106, 3936-3962. http://dx.doi.org/10.1021/cr0509612

[21] Yamago, S., Ukai, Y., Matsumoto, A. and Nakamura, Y. (2009) Organotellurium-Mediated Controlled/Living Radical Polymerization Initiated by Direct C-Te Bond Photolysis. Journal of American Chemical Society, 131, 2100-2101. http://dx.doi.org/10.1021/ja8099689

[22] Tasdelen, M.A., Uygun, M. and Yagci, Y. (2011) Photoinduced Controlled Radical Polymerization. Macromolecular Rapid Communications, 32, 58-62. http://dx.doi.org/10.1002/marc.201000351

[23] Mosnácek, J. and Ilcíková, M. (2012) Photochemically Mediated Atom Transfer Radical Polymerization of Methyl Methacrylate Using ppm Amounts of Catalyst. Macromolecules, 45, 5859-5865.

[24] Koumura, K., Satoh, K. and Kamigaito, M. (2008) Manganese-Based Controlled/Living Radical Polymerization of Vinyl Acetate, Methyl Acrylate, and Styrene: Highly Active, Versatile, and Photoresponsive Systems. Macromolecules, 41, 7359-7367. http://dx.doi.org/10.1021/ma801151s

[25] Jiang, W., Lu, L. and Cai, Y. (2007) Highly Efficient and Well-Controlled Ambient Temperature RAFT Polymerization under Solar Radiation. Macromolecular Rapid Communications, 28, 725-728. 
[26] Otsu, T. and Kuriyama, A. (1984) Living Mono- and Biradical Polymerizations in Homogeneous System Synthesis of AB and ABA Type Block Copolymers. Polymer Bulletin, 11, 135-142. http://dx.doi.org/10.1007/BF00258020

[27] Doi, T., Matsumoto, A. and Otsu, T. (1994) Elucidation of Mechanism for Living Radical Polymerization of Styrene with $\mathrm{N}, \mathrm{N}$-Diethyldithiocarbamate Derivatives as Iniferters by the Use of Spin Trapping Technique. Journal of Polymer Science, Part A: Polymer Chemistry, 32, 2241-2249. http://dx.doi.org/10.1002/pola.1994.080321205

[28] Guillaneuf, Y., Bertin, D., Gigmes, D., Versace, D., Lalevee, J. and Fouassier, J. (2010) Toward Nitroxide-Mediated Photopolymerization. Macromolecules, 43, 2204-2212. http://dx.doi.org/10.1021/ma902774s

[29] Guillaneuf, Y., Versace, D., Bertin, D., Lalevee, J., Gigmes, D. and Fouassier, J. (2010) Importance of the Position of the Chromophore Group on the Dissociation Process of Light Sensitive Alkoxyamines. Macromolecular Rapid Communications, 31, 1909-1913. http://dx.doi.org/10.1002/marc.201000316

[30] Versace, D., Lalevee, J., Fouassier, J., Guillaneuf, Y., Bertin, D. and Gigmes, D. (2010) Photodissociation Rate Constants of New Light Sensitive Alkoxyamines. Macromolecular Rapid Communications, 31, 1383-1388. http://dx.doi.org/10.1002/marc.201000144

[31] Versace, D., Lalevee, J., Fouassier, J., Gigmes, D., Guillaneuf, Y. and Bertin, D. (2010) Photosensitized Alkoxyamines as Bicomponent Radical Photoinitiators. Journal of Polymer Science, Part A: Polymer Chemistry, 48, 2910-2915. http://dx.doi.org/10.1002/pola.24071

[32] Hu, S., Malpert, J.H., Yang, X. and Neckers, D.C. (2000) Exploring Chromophore Tethered Aminoethers as Potential Photoinitiators for Controlled Radical Polymerization. Polymer, 41, 445-452. http://dx.doi.org/10.1016/S0032-3861(99)00188-3

[33] Goto, A., Scaiano, J.C. and Maretti, L. (2007) Photolysis of an Alkoxyamine Using Intramolecular Energy Transfer from a Quinoline Antenna-Towards Photo-Induced Living Radical Polymerization. Photochemical \& Photobiological Sciences, 6, 833-835. http://dx.doi.org/10.1039/b705671k

[34] Yoshida, E. (2008) Photo-Living Radical Polymerization of Methyl Methacrylate by a Nitroxide Mediator. Colloid and Polymer Science, 286, 1663-1666. http://dx.doi.org/10.1007/s00396-008-1930-y

[35] Yoshida, E. (2009) Photo-Living Radical Polymerization of Methyl Methacrylate by 2,2,6,6-Tetra-Methylpiperidine-1Oxyl in the Presence of a Photo-Acid Generator. Colloid and Polymer Science, 287, 767-772. http://dx.doi.org/10.1007/s00396-009-2023-2

[36] Yoshida, E. (2010) Effect of Azoinitiators on Nitroxide-Mediated Photo-Living Radical Polymerization of Methyl Methacrylate. Colloid and Polymer Science, 288, 341-345. http://dx.doi.org/10.1007/s00396-009-2163-4

[37] Yoshida, E. (2010) Stability of Growing Polymer Chain Ends for Nitroxide-Mediated Photo-Living Radical Polymerization. Colloid and Polymer Science, 288, 1027-1030. http://dx.doi.org/10.1007/s00396-010-2230-x

[38] Yoshida, E. (2010) Nitroxide-Mediated Photo-Living Radical Polymerization of Methyl Methacrylate in Solution. Colloid and Polymer Science, 288, 1639-1643. http://dx.doi.org/10.1007/s00396-010-2287-6

[39] Yoshida, E. (2012) Photo-Controlled/Living Radical Polymerization Mediated by 2,2,6,6-Tetramethylpiperidine-1Oxyl in Inert Atmospheres. Colloid and Polymer Science, 290, 1087-1091. http://dx.doi.org/10.1007/s00396-012-2668-0

[40] Yoshida, E. (2012) Effects of Illuminance and Heat Rays on Photo-Controlled/Living Radical Polymerization Mediated by 4-Methoxy-2,2,6,6-Tetramethylpiperidine-1-Oxyl. International Scholarly Research Network (ISRN) Polymer Science, 2012, Article ID: 102186.

[41] Yoshida, E. (2012) Photo-Controlled/Living Radical Polymerization of tert-Butyl Methacrylate in the Presence of a Photo-Acid Generator Using a Nitroxide Mediator. Colloid and Polymer Science, 290, 661-665. http://dx.doi.org/10.1007/s00396-012-2605-2

[42] Yoshida, E. (2012) Photo-Controlled/Living Radical Polymerization of 2-(Dimethylamino)ethyl Methacrylate Using 4-Methoxy-2,2,6,6-Tetramethylpiperidine-1-Oxyl as a Mediator. Colloid and Polymer Science, 290, 965-969. http://dx.doi.org/10.1007/s00396-012-2641-y

[43] Yoshida, E. (2010) Nitroxide-Mediated Photo-Living Radical Polymerization of Vinyl Acetate. Colloid and Polymer Science, 288, 73-78. http://dx.doi.org/10.1007/s00396-009-2123-z

[44] Yoshida, E. (2011) Nitroxide-Mediated Photo-Controlled/Living Radical Polymerization of Ethyl Acrylate. Colloid and Polymer Science, 289, 1127-1132. http://dx.doi.org/10.1007/s00396-011-2435-7

[45] Yoshida, E. (2009) Synthesis of Poly(methyl methacrylate)-block-poly(tetrahydrofuran) by Photo-Living Radical Polymerization Using a 2,2,6,6-Tetramethylpiperidine-1-Oxyl. Colloid and Polymer Science, 287, 1417-1424. http://dx.doi.org/10.1007/s00396-009-2105-1

[46] Yoshida, E. (2011) Graft Copolymerization of Methyl Methacrylate on Polystyrene Backbone through Nitroxide-Mediated Photo-Living Radical Polymerization. Colloid and Polymer Science, 289, 837-841. 
http://dx.doi.org/10.1007/s00396-011-2385-0

[47] Yoshida, E. (2011) Nitroxide-Mediated Photo-Controlled/Living Radical Dispersion Polymerization of Methyl Methacrylate. Colloid and Polymer Science, 289, 1625-1630. http://dx.doi.org/10.1007/s00396-011-2487-8

[48] Yoshida, E. (2010) Nitroxide-Mediated Photo-Living Radical Polymerization of Methyl Methacrylate in the Presence of $\left(\eta^{6}\right.$-Benzene $)\left(\eta^{5}\right.$-cyclopentadienyl)Fe ${ }^{\text {II }}$ Hexafluorophosphate. Colloid and Polymer Science, 288, 1745-1749. http://dx.doi.org/10.1007/s00396-010-2292-9

[49] Yoshida, E. (2010) Nitroxide-Mediated Photo-Living Radical Polymerization of Methyl Methacrylate Using (4-tert-Butylphenyl)diphenylsulfonium Triflate as a Photo-Acid Generator. Colloid and Polymer Science, 288, 239-243. http://dx.doi.org/10.1007/s00396-009-2161-6

[50] Yoshida, E. (2010) Effects of Initiators and Photo-Acid Generators on Nitroxide-Mediated Photo-Living Radical Polymerization of Methyl Methacrylate. Colloid and Polymer Science, 288, 901-905. http://dx.doi.org/10.1007/s00396-010-2220-z

[51] Yoshida, E. (2010) Photo-Living Radical Polymerization of Methyl Methacrylate Using Alkoxyamine as an Initiator. Colloid and Polymer Science, 288, 7-13. http://dx.doi.org/10.1007/s00396-009-2113-1

[52] Yoshida, E. (2012) Aqueous Photo-Living Radical Polymerization of Sodium Methacrylate Using a Water-Soluble Nitroxide Mediator. International Scholarly Research Network (ISRN) Polymer Science, 2012, Article ID: 630478.

[53] Yoshida, E. (2013) Nitroxide-Mediated Photo-Controlled/Living Radical Polymerization of Methacrylic Acid. Open Journal of Polymer Chemistry, 3, 16-22. http://dx.doi.org/10.4236/ojpchem.2013.31004

[54] Miyazawa, T., Endo, T., Shiihashi, S. and Ogawara, M. (1985) Selective Oxidation of Alcohols by Oxoaminium Salts $\left(\mathrm{R}_{2} \mathrm{~N}=\mathrm{O}^{+} \mathrm{X}^{-}\right)$. Journal of Organic Chemistry, 50, 1332-1334. http://dx.doi.org/10.1021/jo00208a047

[55] Yoshida, E., Nakamura, K., Takata, T. and Endo, T. (1993) Oxoaminium Salts as Initiators for Cationic Polymerization of Vinyl Monomers. Journal of Polymer Science, Part A: Polymer Chemistry, 31, 1505-1512. http://dx.doi.org/10.1002/pola.1993.080310620

[56] Kita, Y., Gotanda, K., Murata, K., Suemura, M., Sano, A., Yamaguchi, T., Oka, M. and Matsugi, M. (1998) Practical Radical Additions under Mild Conditions Using 2,2'-Azobis(2,4-dimethyl-4-methoxyvaleronitrile) [V-70] as an Initiator. Organic Process Research \& Development, 2, 250-254. http://dx.doi.org/10.1021/op970059z

[57] Crivello, J.V., Lam, J.H.W., Moore, J.E. and Schroeter, S.H. (1978) Triarylsulfonium Salts: A New Class of Photoinitiators for Cationic Polymerization. Journal of Radiation Curing, 5, 2-17.

[58] Devoe, R.J., Sahyun, M.R.V., Serpone, N. and Sharma, D.K. (1987) Transient Intermediates in the Photolysis of Iodonium Cations. Canadian Journal of Chemistry, 65, 2342-2349. http://dx.doi.org/10.1139/v87-391

[59] Crivello, J.V. and Sangermano, M. (2001) Visible and Long-Wavelength Photoinitiated Cationic Polymerization. Journal of Polymer Science, Part A: Polymer Chemistry, 39, 343-356. http://dx.doi.org/10.1002/1099-0518(20010201)39:3<343::AID-POLA1001>3.0.CO;2-J

[60] Odell, P.G., Veregin, R.P.N., Michalak, L.M., Brousmiche, D. and Georges, M.K. (1995) Rate Enhancement of Living Free-Radical Polymerizations by an Oraganic Acid Salt. Macromolecules, 28, 8453-8455. http://dx.doi.org/10.1021/ma00128a073

[61] Golubev, V.A., Rozantsev, E.G. and Neiman, M.B. (1965) Some Reactions of Free Iminoxyl Radicals with Unpaired Electron Participation. Izvestiya Akademii Nauk SSSR, Seriya Khimicheskaya, No. 11, 1927-1936.

[62] Liu, Y.C., Liu, Z.L., Wu, L.M. and Chen, P. (1985) A Facile Generation of Radical Cations via the Action of Nitroxides. Tetrahedron Letters, 26, 4201-4202. http://dx.doi.org/10.1016/S0040-4039(00)98991-3

[63] Yoshida, E., Ishizone, T., Hirao, A., Nakahama, S., Takata, T. and Endo, T. (1994) Synthesis of Polystyrene Having an Aminoxy Terminal by the Reactions of Living Polystyrene with an Oxoaminium Salt and with the Corresponding Nitroxyl Radical. Macromolecules, 27, 3119-3124. http://dx.doi.org/10.1021/ma00090a001

[64] Yoshida, E., Takata, T., Endo, T., Ishizone, T., Hirao, A. and Nakahama, S. (1994) Convenient Synthesis of Bis-1,3Dithiolium Salt, the Stable Radical Cation by Oxidation with the Oxoaminium Salt. Chemistry Letters, 23, 1827-1828. http://dx.doi.org/10.1246/cl.1994.1827

[65] Rozenberg, V.I., Piotrovskii, V.K., Golubev, V.A., Gvon, K.I., Nikanorov, V.A., Bundel, Y.G. and Reutov, O.A. (1975) Evidence of Intermediate Formation of Particles of Homolytic Nature during Reaction of Organometallic Compounds with 2,2,6,6-Tetramethyl-1-Oxopiperidinium Salts. Izvestiya Akademii Nauk SSSR, Seriya Khimicheskaya, No. 11, 2617-2618.

[66] Yoshida, E. (2012) Selective Controlled/Living Photoradical Polymerization of Glycidyl Methacrylate Using a Nitroxide Mediator in the Presence of a Photosensitive Triarylsulfonium Salt. Polymers, 4, 1580-1589.

http://dx.doi.org/10.3390/polym4031580 
Scientific Research Publishing (SCIRP) is one of the largest Open Access journal publishers. It is currently publishing more than 200 open access, online, peer-reviewed journals covering a wide range of academic disciplines. SCIRP serves the worldwide academic communities and contributes to the progress and application of science with its publication.

Other selected journals from SCIRP are listed as below. Submit your manuscript to us via either submit@scirp.org or Online Submission Portal.
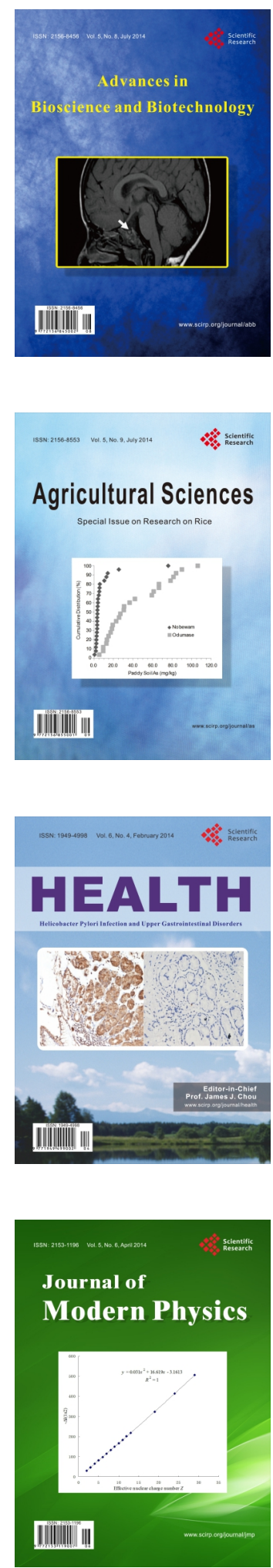
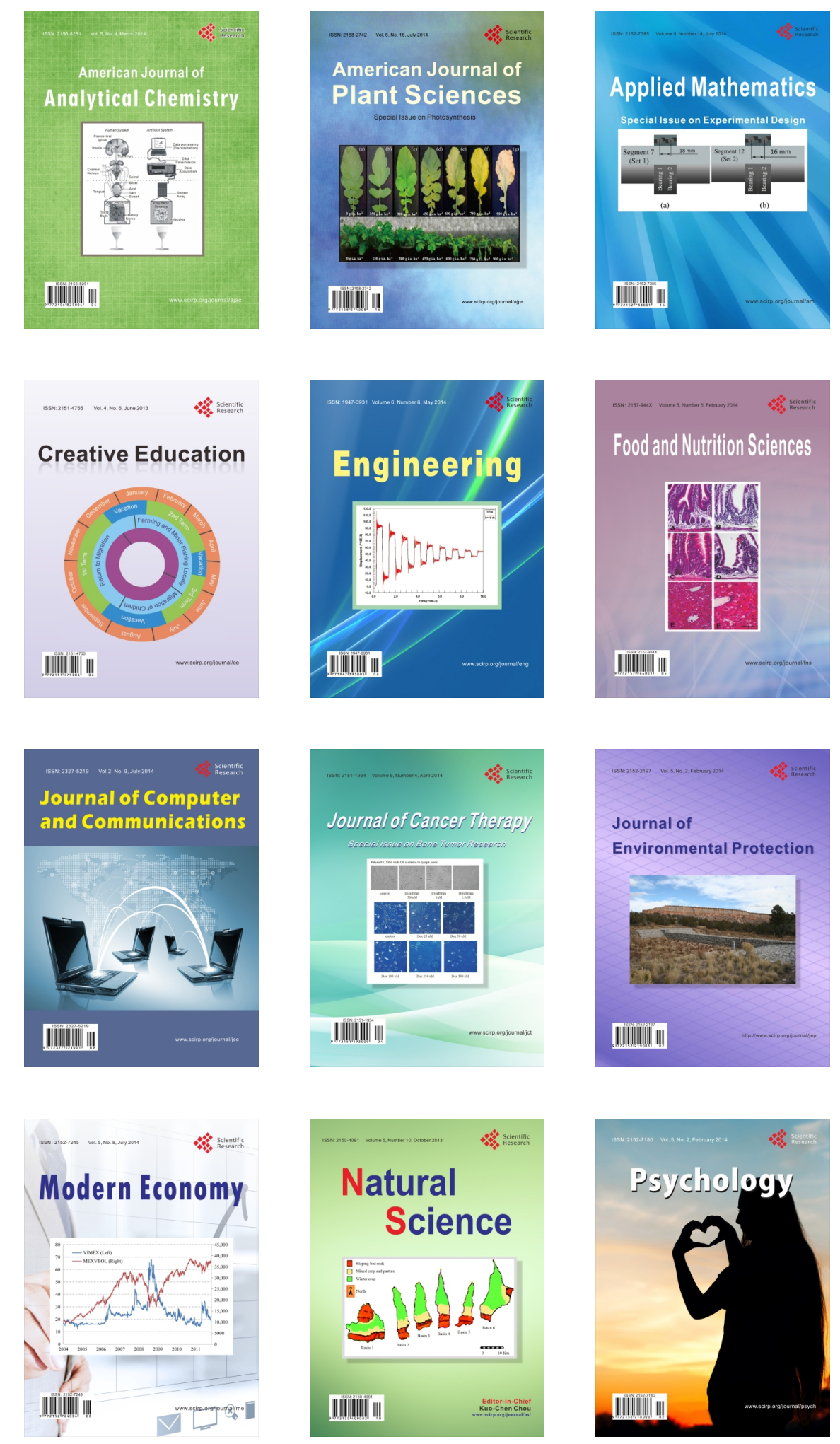